\title{
Biomedical exploration of Bacterial pigments extracted from Staphylococcus sp. and Pseudomonas sp.
}

\author{
Ramya Gunasekaran ${ }^{1}$, Hemapriya Janarthanam ${ }^{2}$ and Vijayanand Selvaraj ${ }^{1 *}$ \\ ${ }^{1}$ Bioresource Technology Lab, Department of Biotechnology, Thiruvalluvar University, \\ Vellore, Tamil Nadu- 632 115, India \\ ${ }^{2}$ Department of Microbiology, DKM College for Women, Sainathapuram, Vellore, \\ Tamil Nadu- 632 001, India \\ *Corresponding author
}

\section{A B S T R A C T}

\begin{tabular}{|c|}
\hline Keywords \\
\hline $\begin{array}{l}\text { Antioxidant, } \\
\text { Antibacterial, } \\
\text { Bacterial pigments, } \\
\text { Extraction, } \\
\text { Optimization }\end{array}$ \\
\hline Article Info \\
\hline $\begin{array}{l}\text { Accepted: } \\
28 \text { June } 2020 \\
\text { Available Online: } \\
10 \text { July } 2020\end{array}$ \\
\hline
\end{tabular}

Bio colorants from microbial resources are highly explored now days for their biotechnological applications. These bio colorants serve asa potential alternate for chemically synthesized coloring agents and also numerous biomedical applications. This study deals with the isolation and optimization of chromogenic bacteria from different soil samples. The bacterial isolates (BRT-CB1 and BRTCB2) were further subjected to pigment extraction using methanol and chloroform as active solvents. Extracted pigments were evaluated for its antioxidant efficiency against DPPH as free radical. The extracted pigments scavenge free radical with increasing concentration. The antagonistic ability of the pigments were studied on selected bacterial pathogens such as Bacillus subtilis, E. coli, Shigella sp., Klebsiella sp. and Streptococcus pyogenes where the inhibitory activity was found to be directly proportional with the increasing concentration of pigment. Thus, the work concludes that bacterial pigments are prospective metabolite which can be applied in biotechnological and biomedical applications.

\section{Introduction}

Natural pigments acquired a key status in therapeutic and industrial applications due to its nontoxic, biocompatibility, safe and ecofriendly nature. In early periods, plants and algae were considered as the best source of natural colorants. Later, microbes were considered to be one of the effective resources of pigments. Algae, fungi and bacteria are few potential microbes which produce pigments with numerous biological applications (Tuli et al., 2015).

Among various sources, chromogenic bacteria play a key role due its unique features such as utilization of low-cost growth supplements, shorter fermentation time, high yield and easy extraction procedure which makes them a better candidate in research and industrial uses (Venil et al., 2014). Currently bacterial pigments are highly utilized in 
pharmaceutical, food and textile industries for its biological activities such as antimicrobial, antioxidant, anti-inflammatory, antibiofilm formation and anticancerous properties. Bacteria were reported to produce various pigments such as Indigoidine, Carotenoids, Prodigiosin, Pyocyanin, Pyoverdine, Violacein and Melanin. Apart from industrial applications, bacterial pigments play an essential role in defense mechanism against photooxidation (Franceschelli et al., 2014).

Free radicals generated in the microbial cells are responsible for oxidative stress and cellular damage. Carotenoids are group of yellow - orange pigments responsible for its antioxidant and anticancerous properties. These dietary substances scavenge the ROS molecules thereby decrease the adverse effects (Kodach et al., 2006). Under oxidative stress, the carotenoid molecules act as antioxidant and enhances the cellular integrity and stability (Ungureanu and Ferdes 2012).

On the other hand, due to the discovery of numerous synthetic antibiotics the microbial flora has acquired an undesirable feature called Multi Drug Resistance (MDR). MDR bacteria creates a challenging situation for development of antibacterial drugs against them(Keith et al., 2000). Natural pigments from bacteria possess a unique defense property which inhibits the growth of MDR bacterial species (Tuli et al., 2013).

Pyoverdine, extracted from Pseudomonas sp, were reported for its antagonistic activity against several MDR bacteria. In the present study, carotenoid producing bacterial strain and Pyoverdine producing Pseudomonas sp. has been isolated and optimized for production of maximum pigment yield. Further the pigments from the strain were further studied for its antioxidant and antibacterial properties.

\section{Materials and Methods}

\section{Sample collection and isolation of chromogenic bacteria}

Soil samples from three different sites (A1, A2 and A3) were collected in a sterile polythene bag aseptically and designated accordingly. Samples were serially diluted in autoclaved water and plated over freshly prepared nutrient agar plate and incubated for $48 \mathrm{~h}$ at $37^{\circ} \mathrm{C}$. Following incubation, the plates were observed for presence of chromogenic colonies. The selected strains were purified and designated as BRT- CB1 and BRT-CB2. The isolates were purified using purification techniques and stored at $4^{\circ} \mathrm{C}$ for further uses. The isolates were subjected to morphological and biochemical characterization.

\section{Optimization of growth condition for maximum pigment production}

\section{Effect of pH on pigment production}

To determine the effect of $\mathrm{pH}$ on pigment yield, the isolates were inoculated separately in $100 \mathrm{ml}$ of freshly prepared nutrient broth culture. The $\mathrm{pH}$ of the nutrient media was altered using sodium hydroxide and $\mathrm{HCl}$ to varying levels of $\mathrm{pH}$ from 2 to 9. The intensity of the pigment production was determined using spectrometric analysis at $\mathrm{OD}_{600} \mathrm{~nm}$.

\section{Effect of temperature on pigment production}

To evaluate the optimum temperature required for the production of maximum yield, $100 \mathrm{ml}$ of freshly prepared nutrient broth culture was inoculated with the isolated cultures (BRT-CB1 and BRT-CB2). The cultures were further incubated at varying temperature ranging from $20^{\circ} \mathrm{C}$ to $60{ }^{\circ} \mathrm{C}$. The effect of temperature on pigment production 
was determined using spectrometric analysis at $\mathrm{OD}_{600} \mathrm{~nm}$.

\section{Effect of time on pigment production}

To estimate the optimum incubation time required for the pigment production, $100 \mathrm{ml}$ of freshly prepared nutrient broth were inoculated with the isolates (BRT-CB1 and BRT-CB2). The growth of the bacterial cultures was observed at regular time intervals $(6 \mathrm{~h})$. The effect of time on pigment production was determined using spectrometric analysis at $\mathrm{OD}_{600} \mathrm{~nm}$.

\section{Extraction of pigment}

\section{Yellow pigment extraction from BRT-CB1}

$100 \mathrm{ml}$ of freshly prepared nutrient broth media was incubated with active culture of BRT-CB1 and incubated at $30{ }^{\circ} \mathrm{C}$ for $48 \mathrm{~h}$. Following incubation, the culture media was transferred to sterile centrifuge tube and centrifuged at $8000 \mathrm{rpm}$ for 15 minutes. The cell pellet was subjected to washing using distilled water and recentrifuged. Further, the pellet was treated with methanol and kept undisturbed for $4 \mathrm{~h}$. Later the solvent- pellet mixture was centrifuged and the pigment in the supernatant was collected in a fresh tube.

\section{Green pigment extraction from BRT-CB2}

$100 \mathrm{ml}$ of freshly prepared nutrient broth was inoculated with $24 \mathrm{~h}$ active culture of BRT$\mathrm{CB} 2$ and incubated at $30{ }^{\circ} \mathrm{C}$ for $48 \mathrm{~h}$. The water-soluble green pigment was extracted using chloroform and $\mathrm{HCl}$. The active culture was centrifuged at $8000 \mathrm{rpm}$ for $10 \mathrm{~min}$. The supernatant was collected and treated with chloroform (1:2). The upper layer was collected in a sterile glass tube and treated with $\mathrm{HCl}$. The acidified layer was neutralized using Tri-base. The procedure was repeated for three times and the pigment was collected in a sterile collecting tube (Devnath et al., 2017).

\section{Antioxidant activity of the bacterial pigments}

\section{Free radical scavenging assay using DPPH}

Radical scavenging ability of the pigments extracted from the isolates (BRT-CB1 and BRT-CB2) was studied using DPPH assay. $1 \mathrm{ml}$ of DPPH solution $(0.1 \mathrm{mM})$ was mixed with $3 \mathrm{ml}$ of pigments extracted from BRTCB1 and BRT-CB2 at varying concentrations ranging from $(100-500 \mu \mathrm{g} / \mathrm{ml})$. The mixture was mixed well and incubated for $1 \mathrm{~h}$. The absorbance was recorded at $517 \mathrm{~nm}$ using UV-Vis spectrophotometry (Brand-Williams et al., 1995). The percentage of inhibition was calculated using the equation

\section{DPPH scavenging effect $(\%)=A_{0}-A_{1} / A_{0} X 100$}

Where, $\mathrm{A}_{0}$ represent control and $\mathrm{A}_{1}$ represents the absorbance of test sample (pigment)

\section{Antibacterial activity of the bacterial pigments}

Pigments extracted from chromogenic bacterial isolates (BRT-CB1 and BRT-CB2) were investigated for its antibacterial activity against bacterial pathogens such as Bacillus subtilis, E. coli, Shigella sp., Klebsiella sp. and Streptococcus pyogenes. Freshly prepared Muller Hinton agar plates were used for determining the antagonistic activity using well diffusion method. Wells were cut using sterile well cutter and overnight broth cultures of the selected bacterial pathogens were swabbed over the agar. Varying concentrations $(20-100 \mu \mathrm{g} / \mathrm{ml})$ of pigments was loaded and incubated at $37^{\circ} \mathrm{C}$ for $24 \mathrm{~h}$. Following incubation, the plates were observed for the zone of inhibition (Saha et al., 2008). 


\section{Results and Discussion}

\section{Isolation and identification of BRT-CB1 and BRT-CB2}

Two distinct chromogenic bacterial strains were isolated from soil samples. The isolates were studied for its morphological and biochemical characterizations. The colony morphology of BRT-CB1 on nutrient agar plate was found to be circular, convex, and smooth with golden yellow pigmentation. On the other hand, the morphology of BRT-CB2 was observed to be irregular, smooth, and convex with bluish green pigmentation. According to the analysis the isolate BRTCB1 was found to be Staphylococcus sp. The isolate was observed to be catalase positive and could efficiently grow on the mannitol salt agar plate utilizing the mannitol which is a characteristic feature of Staphylococcus sp. (Parija 2012). Based on the microscopic and biochemical analysis the isolate BRT-CB2 was found as Pseudomonas sp. belonging to Pseudomonadaceae family. Pseudomonas sp. being considered as a human pathogen was reported to produce medicinally important secondary metabolites such as pigments, enzymes and toxins (Rubilar et al., 2008).

\section{Optimization of growth conditions for maximum pigment production}

Optimization of growth conditions such as $\mathrm{pH}$, temperature, agitation and incubation time play a key role in enhancing the yield of the byproduct and also responsible for the production of bacterial biomass. The isolate BRT-CB1, was found to produced maximum pigment when incubated with $\mathrm{pH} 6$ to 7 . On the other hand, the intensity of the pigment production in isolate BRT-CB2 was found to be maximum when incubated at $\mathrm{pH} 8$ (Fig 1). The isolate BRT-CB1 was observed to produce maximum pigment at $30{ }^{\circ} \mathrm{C}$ whereas the isolate $\mathrm{BRT}-\mathrm{CB} 2$ produced maximum pigmentation at $20^{\circ} \mathrm{C}$ (Fig 2). Incubation time is one of the essential factors for determination of percentage of secondary metabolite extracted. BRT-CB1 showed high pigmentation when incubated for $48 \mathrm{~h}$, where as maximum pigmentation was observed at 36 $h$ in BRT-CB2 (Fig 3).

\section{Antioxidant activity of the isolates}

Antioxidant ability of the extracted pigment was studied using DPPH assay. The antioxidant efficiency of the pigment was determined based on the percentage of inhibition. The pigment extracted from BRTCB1 shows effective radical scavenging ability at $200 \mu \mathrm{g} / \mathrm{ml}$ when compared with the other pigment (Fig 4). Previous study states that, free radical scavenging ability of carotenoids are mediated by the conjugated double bonds present in the structure (Clauditz et al., 2006). These bonds make the carotenoid pigment more stable and enhance the radical scavenging ability more effective (El-Agamey et al., 2004).

\section{Antibacterial activity of bacterial pigments}

Antagonistic ability of the bacterial pigments was studied using well diffusion method against five different pathogenic bacterial strains. Pigment extracted from BRT-CB1 exhibited maximum zone of inhibition against Bacillus subtilis (16mm) and Streptococcus pyogenes $(15 \mathrm{~mm})$, however average range of inhibition was noted against Shigella sp. and Klebsiella sp. Minimum inhibition was observed against E.coli (6 mm) (Fig 5A). Whereas, the antagonistic activity of pigment extracted from BRT-CB2 was more effective. The pigment exhibited maximum zone of inhibition against Bacillus subtilis $(17 \mathrm{~mm})$, Streptococcus pyogenes (15mm) and Klebsiella sp. (15 mm). Minimum zone of inhibition was observed against E.coli $(8 \mathrm{~mm})$ and Shigella sp (7 mm) (Fig 5B). Similarly, antibacterial activity of staphyloxanthin extracted from Staphylococcus gallinarum was reported to be effective against E. coli, Staphylococcus aureus and Candida albicans (Barretto 2018). 


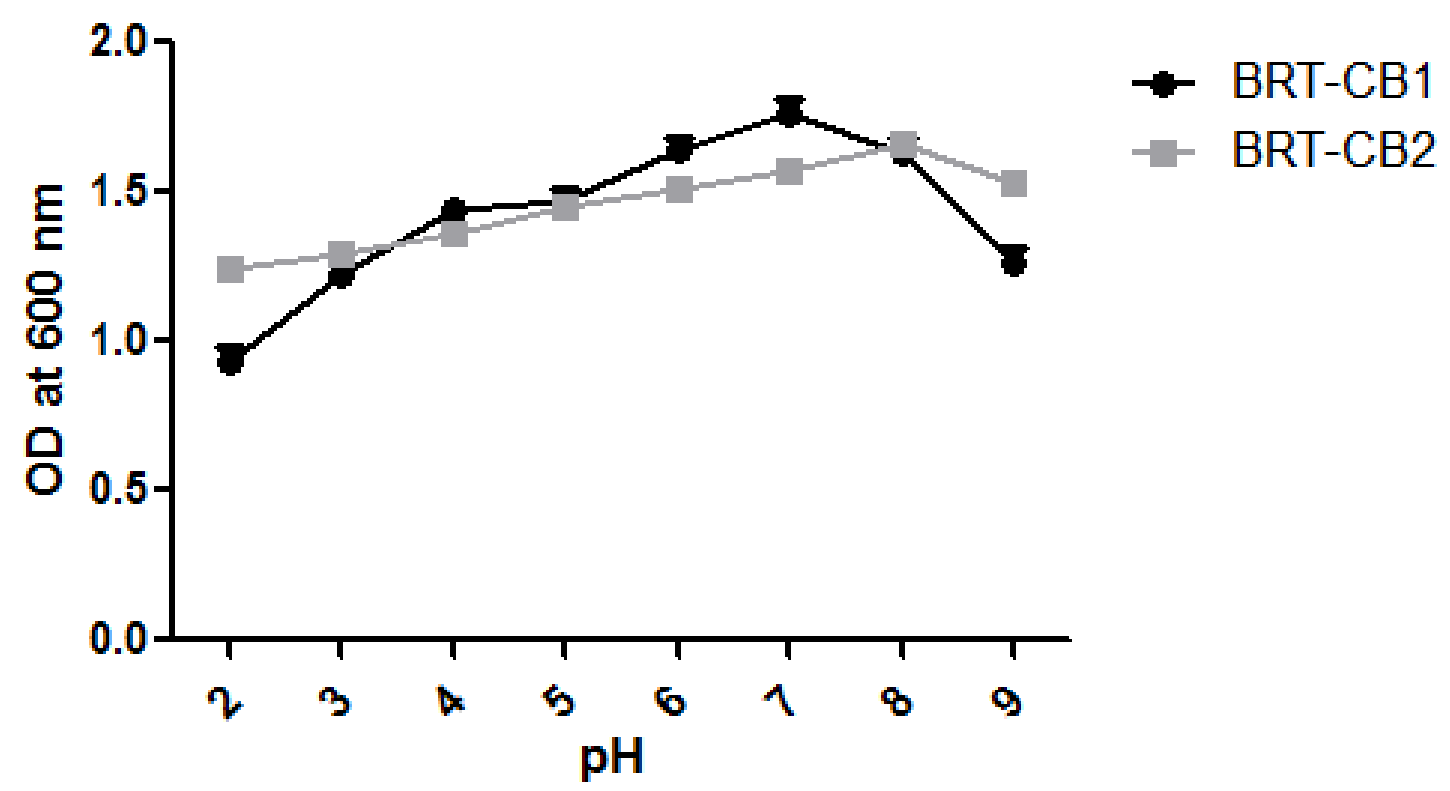

Figure.1 Effect of $\mathrm{pH}$ on pigment production of BRT-CB1 and BRT-CB2

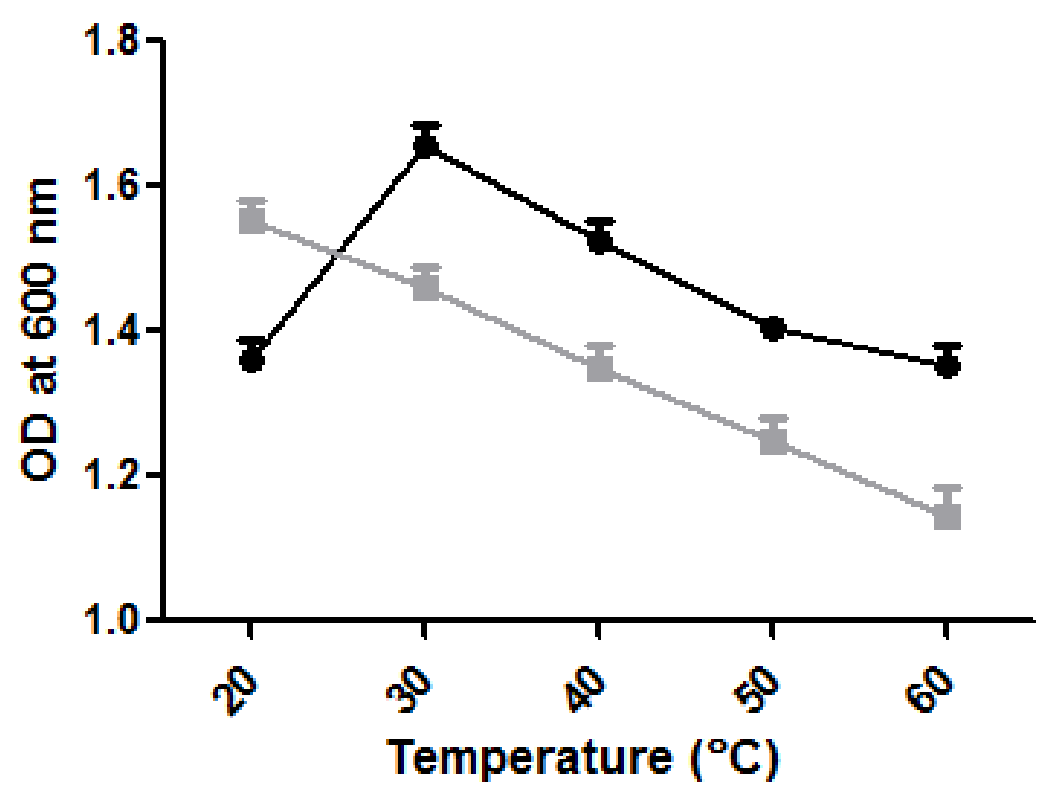

* BRT-CB1

- BRT-CB2

Figure.2 Effect of temperature on pigment production of BRT-CB1 and BRT-CB2 


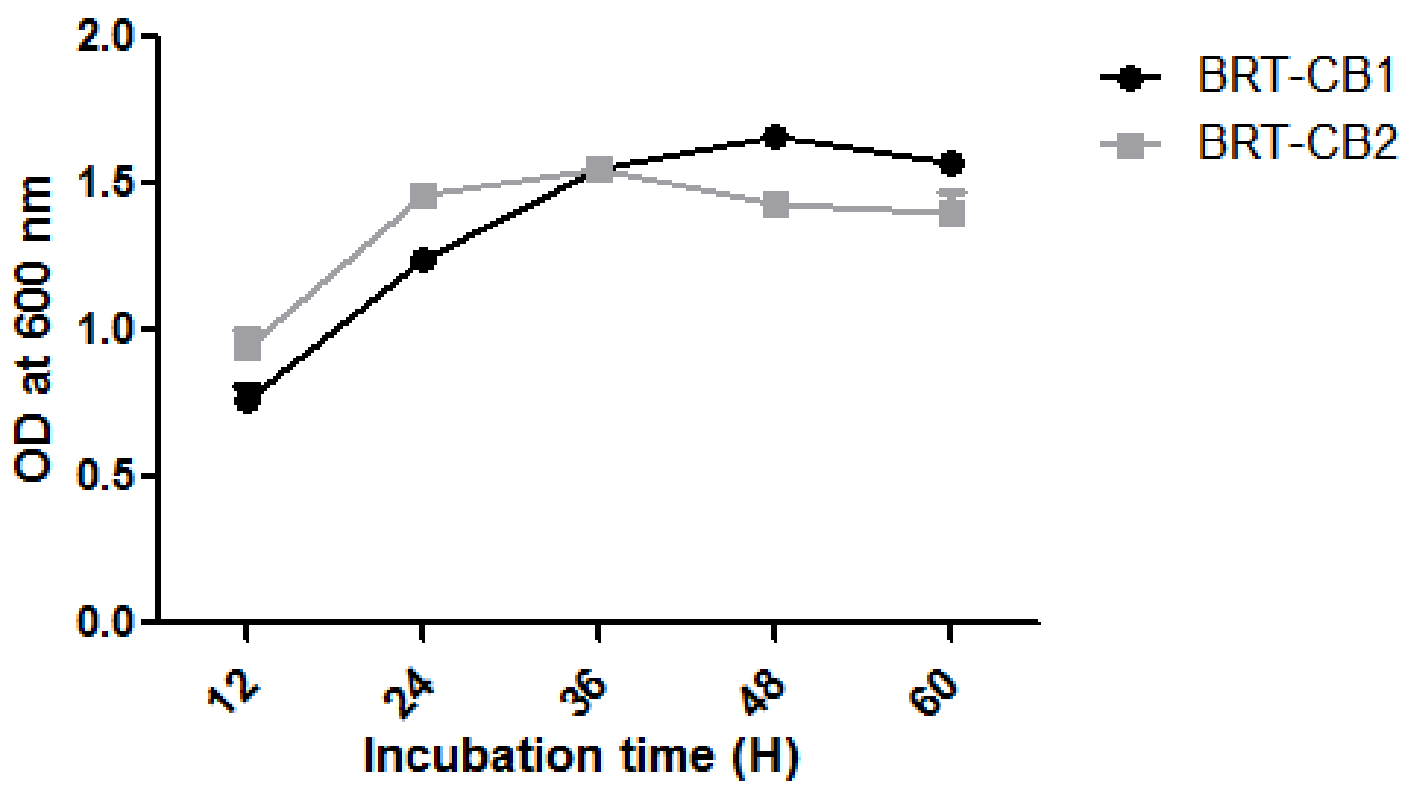

Figure.3 Effect of incubation time on pigment production of BRT-CB1 and BRT-CB2

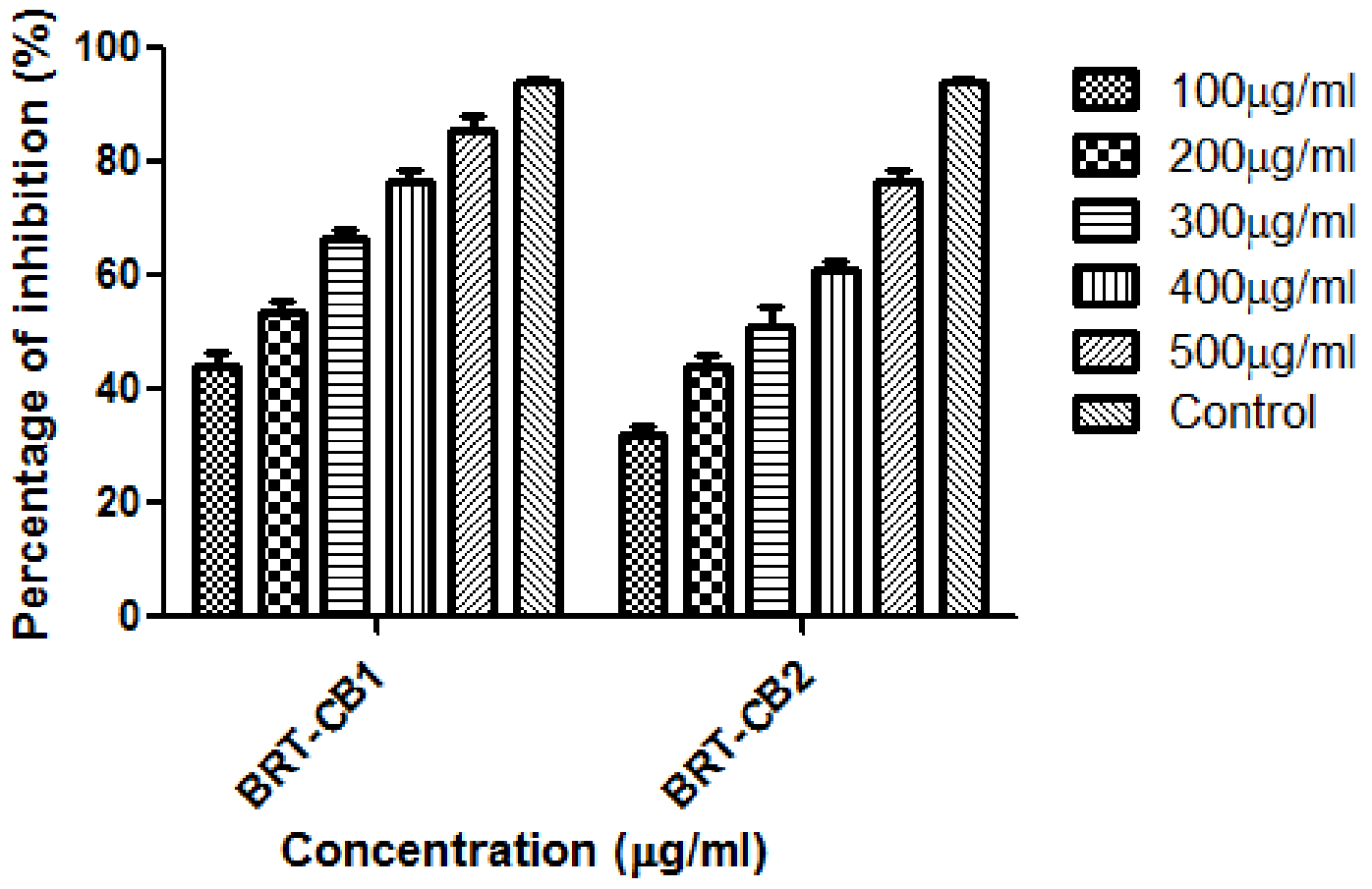

Figure.4 Antioxidant ability of pigment extracted from the isolates (BRT-CB1 and BRT-CB2) 


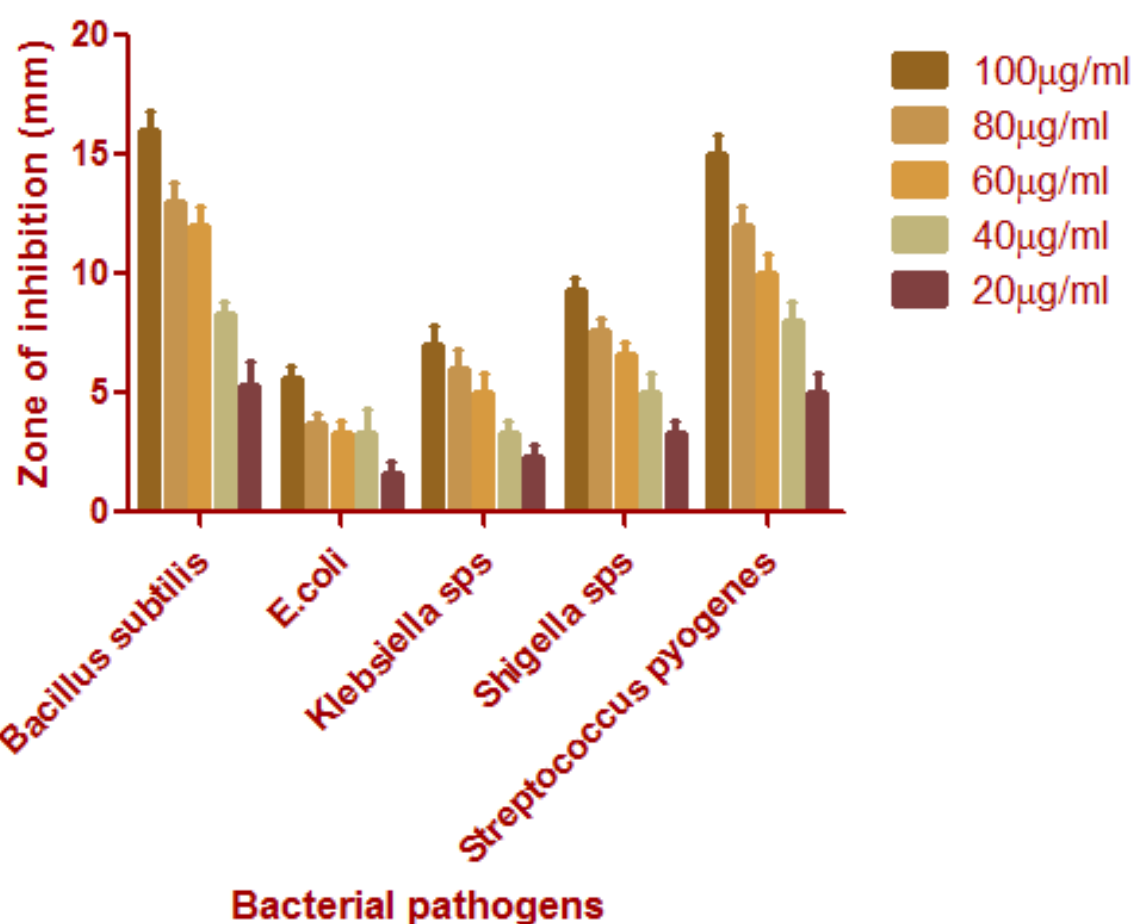

Figure.5 A. Antibacterial activity of pigment extracted from BRT-CB1

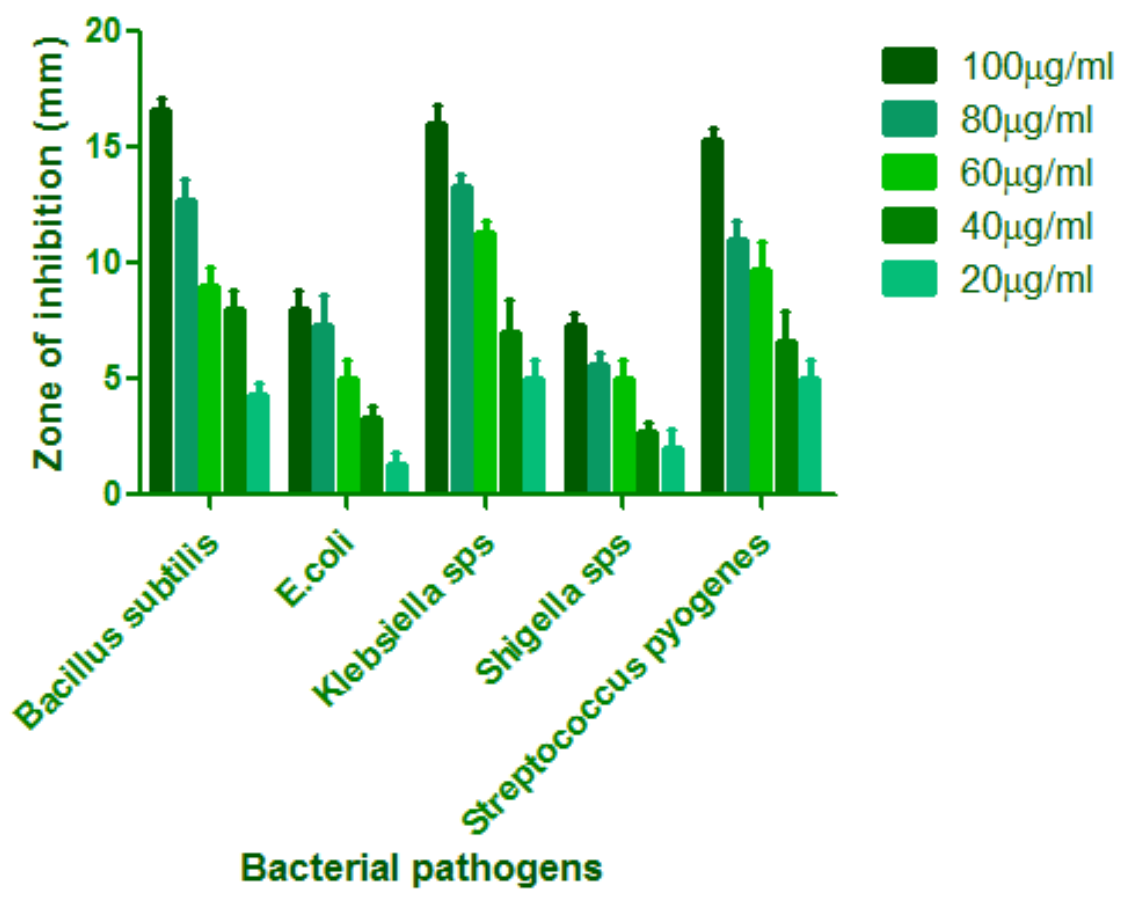

Figure.5 B. Antibacterial activity of bacterial pigment extracted from BRT-CB2

Pigments extracted from natural resources serve as potential substitute for chemically synthesized colorants. The present study demonstrated the biological properties of 
bacterial pigments extracted from soil bacteria. It is been evident that bacterial pigments act as promising candidate in biotechnological applications. The radical scavenging against DPPH and antagonistic ability of chromogenic bacteria against pathogenic bacteria paves a way for exploiting these natural colorants in therapeutics and biomedical application.

\section{References}

Barretto DA (2018) In Vitro Anticancer Activity of Staphyloxanthin Pigment Extracted from Staphylococcus gallinarum KX912244 , a Gut Microbe of Bombyx mori. Indian J Microbiol https://doi.org/10.1007/s12088-018-0718-0

Brand-Williams W, Cuvelier M, Berset C (1995) Use of a free radical method to evaluate antioxidant activity. Leb Wiss Technol 28:25-30.

Clauditz A, Resch A, Wieland K, Peschel A, Goltz F (2006) Staphyloxanthin plays a role in the fitness of Staphylococcus aureus and its ability to cope with oxidative stress. Infect Immun 74:4950 4953.

Devnath P, Uddin K, Ahamed F (2017) Extraction, Purification and Characterization of pyocyanin produced by Pseudomonas aeruginosa and evaluation for its antimicrobial activity Int Res J Biol Sci 6:1-7

El-Agamey A, Lowe G, McGarvey D, Mortensen A, Phillip D, Truscott T, Young A (2004) Carotenoid radical chemistry and antioxidant/pro-oxidant properties. Arch Biochem Biophys 430:37-48.

Franceschelli S, Pesce M, Ferrone A, Lutiis MA De, Patruno A, Grilli A, Felaco M, Speranza L (2014) Astaxanthin Treatment Confers Protection against Oxidative Stress in U937 Cells Stimulated with Lipopolysaccharide Reducing $\mathrm{O} \quad 2 \quad 2$ Production. PLoS One 9:1-9. https://doi.org/10.1371/journal.pone.00883
59

Keith S, Kaye M, Donald Kaye M (2000) Multidrug-resistant pathogens: mechanisms of resistance and epidemiology. Curr Infect Dis Rep 2:391398

Kodach L, Bos C, Durán N, Peppelenbosch M, Ferreira C, Hardwick J (2006) Violacein synergistically increases 5-fluorouracil cytotoxicity, induces apoptosis and inhibits Akt-mediated signal transduction in human colorectal cancer cells. Carcinogenesis 27:508-516

Parija S (2012) Textbook of microbiology and immunology,. 2nd edn Elsevier, India, 174

Rubilar O, Diez MC, Gianfreda L (2008) Transformation of chlorinated phenolic compounds by white rot fungi. Crit Rev Environ Sci Technol 38:227-268.

Saha S, Thavasi R, Jayalakshmi S (2008) Phenazine Pigments from Pseudomonas aeruginosa and Their Application as Antibacterial Agent and Food Colourants,. Res J Microbiol 3:122-128.

Tuli H, Sharma A, Sandhu S (2013) Pharmacological and Therapeutic potential of Cordyceps with special reference to Cordycepin. 3Biotech DOI 10.1007/s13205-013-0121-9.

Tuli HS, Chaudhary P, Beniwal V (2015) Microbial pigments as natural color sources: current trends and future perspectives. J Food Sci Technol 52:46694678 . https://doi.org/10.1007/s13197-0141601-6

Ungureanu C, Ferdes M (2012) Evaluation of antioxidant and antimicrobial activities of torularhodin. Adv Sci Lett 18:50-53

Venil CK, Aruldass CA, Dufossé L, Zakaria ZA, Ahmad WA (2014) Current perspective on bacterial pigments: emerging sustainable compounds with coloring and biological properties for the industry - an incisive evaluation. RSC Adv 4:39523

https://doi.org/10.1039/C4RA06162D 
How to cite this article:

Ramya Gunasekaran, Hemapriya Janarthanam and Vijayanand Selvaraj. 2020. Biomedical exploration of Bacterial pigments extracted from Staphylococcus sp. and Pseudomonas sp. Int.J.Curr.Microbiol.App.Sci. 9(07): 4060-4068. doi: https://doi.org/10.20546/ijcmas.2020.907.476 